\title{
EL ARTISTA DEL EXILIO ESPAÑOL DE 1939 EN MÉXICO. ESTUDIO DEL TEMA DESDE 1975
}

\author{
POR \\ MIGUEL CABAÑAS BRAVO \\ Departamento de Historia del Arte del CSIC
}

This article deals with the studies since 1975 about the Spanish artist exiled in México.

\section{Un fenómeno mal conocido}

Uno de los fenómenos más llamativos del arte español de nuestro siglo y, a la vez, uno de los peor conocidos por nuestra historiografía, es el de la diáspora de una parte bastante elevada y significativa de nuestros artistas tras la guerra civil y sus consecuencias posteriores.

La dispersión fue amplia y, analizar las características y dimensión de la actividad de este artista republicano en cada uno de los núcleos de asiento o tránsito, excedería mi propósito, que se halla orientado hacia el análisis de la atención que ha merecido el tema del artista español exiliado en México, el país que mayor número de creadores terminó acogiendo y aclimatando, dotándoles con ello de unas especiales características configuradoras.

En este sentido, además de hacer balance sobre la situación en la que se encuentra el estudio de este tema — sobrepasando el período exacto del exilio político, que acababa en $1977^{1}$ - , mi intención es que el breve análisis presentado sirva de punto de partida a un trabajo más en profundidad sobre la escena y trayectoria que, durante más de cincuenta años, siguió en México là actividad del artista español transterrado, por emplear el arraigado neologismo inventado por José Gaos ${ }^{2}$.

1 La muerte de Franco en noviembre de 1975 abrió un nuevo momento en cuanto al viejo desconocimiento mexicano del gobierno franquista, momento durante el que se fueron preparando las bases para la reanudación de las relaciones diplomáticas entre ambos países, aunque previamente hacía falta liquidar el asunto del gobierno de la República Española en el exilio, único que había reconocido México desde 1945. No obstante, las medidas concretas no se tomaron esta el mandato, iniciado en diciembre de 1976, del nuevo presidente mexicano, José López Portillo, que sucedía a Luis Echeverría. El 18 de marzo de 1977, López Portillo y José Maldonado, último presidente de la República Española en el exilio, anunciaron públicamente la cancelación de relaciones diplomáticas entre sus respectivos gobiernos, y diez días después México reconocía al gobierno de Juan Carlos I, dando definitivamente por finalizado el exilio político español. Vid. Fuentes Mares, José: Historia de dos orgullos, México D.F., Océano, 1984, pp. 188-212 y Meyer, Eugenia (coor.): Palabras del Exilio 4. De los que volvieron, México D.F., INAH (SEP)-Instituto Mora, 1988, pp. 52-53.

Consideraba Gaos que este término, hacia 1949, definía mejor al republicano español adaptado en un nuevo país, a quien decía que ya no podía seguir llamándosele desterrado o exiliado. Vid. Gaos, José: «Los transterrados españoles en la filosofía de México», Filosofía y Letras, n. 36, México D.F., oct.-dic. 1949; En torno a la filosofía mexicana, vol. II, México D.F., Porrúa y Obregón, 1953, p. 83; y «La adaptación de un español a la sociedad hispano-americana», Revista de Occidente, n. ${ }^{4}$, Madrid, Mayo 1966, pp. 168-178. 
Quizá no estuviera de más profundizar en lo escrito sobre cada uno de estos artistas, en su inmensa mayoría con una trayectoria artística en México mal y escasamente conocida en nuestro país. Pero, dada su abundante nómina, apenas podríamos dedicarnos a algunos de ellos y, lógicamente, sería difícil eludir a los más conocidos: Remedios Varo, José Renau, Antonio Rodríguez Luna, José Moreno Villa, Ramón Gaya, Enrique Climent, Vicente Rojo, etc., quienes precisamente ya disponen de estimables monografías. Preferentemente, pues, conviene dirigir los comentarios hacia planteamientos amplios del fenómeno del exilio mexicano, ya que estos enfoques, abundantes en otras materias, realmente son escasos en los estudios del hecho artístico.

$\mathrm{Y}$ es que analizar este tema en conjunto no es fácil, ya que nos encontramos ante un fenómeno ancho y complejo, que abarca más de medio siglo de desarrollo de nuestro arte contemporáneo al otro lado del Océano, con sus consiguientes cambios de orientación y una marcada desconexión respecto al curso seguido por la creatividad artística en suelo peninsular.

Desde la perspectiva española, hay que considerar hoy, sin entrar a juzgar la historia, que la separación que propició el resultado de la guerra civil, lejos de representar una significativa amputación, una pérdida o una mengua del arte contemporáneo español, como durante mucho tiempo quiso verse, representa un enriquecimiento de su sustrato y campo de acción. Y México, en este sentido, constituye un caso paradigmático, tanto por la abundancia en la recepción de artistas españoles como por la ampliación y peculiar desarrollo que éstos hicieron de las formas y tendencias españolas de acercamiento al arte.

No obstante, para que se produzca este ensanche de las visiones manejadas en nuestras historias del arte del siglo XX, como se ha puesto de manifiesto en repetidas ocasiones, incluso haciéndose notar la diferencia con el conocimiento y análisis del exilio literario, se necesita de estudios solventes que aborden en profundidad la cuestión artística ${ }^{3}$.

Esta carencia es aun más llamativa si consideramos el empeño que pusieron los republicanos españoles en registrar su esfuerzo y en que su labor transcendiera ${ }^{4}$. Además, el hecho

3 Así, por ejemplo, sobre estas carencias señalaba Valeriano Bozal en 1993, sin que aún haya variado demasiado la situación: «El exilio artístico no es tema que se haya estudiado con detenimiento, desde luego con mucha menor dedicación que el exilio literario, y todavía falta por hacer una exposición que agrupe las principales obras de los exiliados españoles. Por el momento, debemos contentarnos con las manifestaciones más conocidas y las más conocidas publicaciones, muchas veces con los datos escuetos de las biografías personales de artistas que tampoco han sido estudiados de forma monográfica». Insistiendo más adelante: «Carecemos todavía de un estudio solvente sobre el arte español en el exilio y por tanto hemos de mantener hipótesis provisionales y muchas veces fundadas en sugerencias o en documentos parciales» (Bozal, V.: Pintura y escultura españolas del Siglo XX (1939-1990), vol. XXXVII de Summa Artis, Madrid, Espasa Calpe, 1993, pp. 78 y 80).

4 El hecho, con todo, no es comparable en cuanto a los registros de la labor literaria y artística, siendo bastante menores en esta última. No obstante, aparte de las exposiciones celebradas en diferentes momentos, cuya realización obedeció a diversos motivos que más adelante comentaremos, y de las muestras y estudios monográficos de artistas determinados, véase sobre las intenciones de hacer recuento y balance de la actuación de los artistas desterrados en el transcurso mismo del exilio: Arveras Oria, C.: «Arte español en el exilio», España 1941, n. ${ }^{\circ}$ 1, Bogotá, Octubre 1941, p. 19; Renau, José: «La defensa del Tesoro Artístico Español», Ars, n.․1, México D.F., Febrero 1942; Fresco, Mauricio: La emigración republicana española, una victoria de México, México D.F., Editores Asociados, 1950, pp. 84-85 y 146-150; Giner de los Ríos, Bernardo: 50 Años de Arquitectura Española (1900-1950), México D.F., Editorial Patria, 1952, pp.; Fernández Balbuena, Roberto: «Agonía y resurrección del Museo del Prado», Boletín de Información. Unión de Intelectuales Españoles, n.o 1, México D.F., 15-VIII-1956, pp. 9-10; «La obra de los desterrados españoles en México», Boletín de Información. Unión de Intelectuales Españoles, n.․ 5, México D.F., Junio-Septiembre 1957, especialmente pp. 21-23; Martínez, Carlos: Crónica de una emigración: la de los republicanos españoles, México D.F., Libro-Mex, 1959, especialmente pp. 133-157; Fagen, Patricia W.: Transterrados y ciudadanos. Los republicanos españoles en México, México D.F, FCE, 1975 (1973), especialmente pp. 64-65. 
se agrava de una manera evidente para el caso del exilio mexicano, puesto que en él se aúnan varios factores importantes. Entre éstos podríamos señalar, en primer lugar, un comienzo del interés historiográfico más tardío que el caso de la tradicional emigración-exilio del artista español a Francia, más estudiado y digerido que el del artista asentado al otro lado del Océano; en segundo, la abundante y mal conocida nómina de artistas españoles llegados a México a partir de 1939 (solamente en los que yo he registrado en mis investigaciones estaríamos hablando de cerca de 300 creadores exiliados en este país, bien que de diferentes generaciones y grado de formación y dedicación al arte), o, en tercer lugar, la peculiaridad tanto de algunas de las técnicas empleadas —el muralismo, la gráfica, el cartel—, como de ciertas tendencias artísticas seguidas por muchos de nuestros artistas llegados al país azteca (algunas tan interesantes para ampliar los registros del arte español como la del realismo socialista, que si bien no pudo prosperar en el suelo peninsular, por razones evidentes, si tuvo un singular desarrollo en México, que debiera ser recogido en los manuales españoles de historia del arte, puesto que se trata de una notable tendencia y una singular faceta de la creación española de este siglo).

Pero lo cierto es que, como veremos más adelante, a partir de 1975 el estudio del fenómeno del exilio artístico - en el que, con todo, nunca se había profundizado ni se profundizaría tanto como en el literario- iba a quedar en manos de las circunstancias socio-políticas. A éstas interesó, sobre todo, hacer exposiciones conmemorativas, unas veces de aspectos muy localizados y, otras, de conjuntos culturales demasiado amplios, lo cual terminó condicionando fuertemente la visión del artista exiliado, inmerso siempre en los grandes paisajes culturales, pero sin que su figura obtenga el suficiente relieve y amplitud de estudio. Tiempo es ya de que aumenten esas escasas incursiones monográficas en el fenómeno y de que se trate el tema en profundidad, sin apasionamientos ni oportunismos.

\section{Los años 70: La emergencia de un viejo tema}

Respecto al artista español emigrado a México no hay que pensar, pese a la insuficiencia, que partimos de un páramo historiográfico.

Desde 1975, poco antes de la muerte del general Franco, en aquel país americano la iniciativa privada comenzó a hacer recuento de la actividad artística de los exiliados a través de exposiciones, siendo pionera la organizada, en su capital, por la Galería Mercedes y Jordi Gironella en estrecho contacto con Antonio Rodríguez Luna, presentada bajo el rótulo: «Pintores y Escultores Republicanos en México». En su catálogo, el poeta y ensayista transterrado Tomás Segovia, analizaba la huella dejada por la emigración española en México. Presentía que, en los próximos años, ésta comenzaría «a ser examinada con más objetividad y menos sentimentalismo». Ciertamente, además, la obra de los pintores refugiados — hallaba— parecía haber quedado «más en la sombra» que la de los literatos, pero acaso empezara a poner remedio, pensaba, la muestra inaugurada por esta galería ${ }^{5}$. Sin embargo, la cuestión sería más lenta.

\footnotetext{
5 Argumentaba Segovia: «Curioso que una expresión visual, y más en México, salga menos a la luz que la expresión verbal que le corresponde. Tal vez lo que pasó es que entre España y México la lengua era la misma pero el ojo otro. O tal vez la literatura (la poesía sobre todo) y el pensamiento mexicanos de aquella época estaban más abiertos que sus artes visuales. $O$ tal vez lo que la plástica española traía era menos adecuado, o menos innovador, o menos necesario que lo que traían las letras, porque lo que pasó en España en la creación literaria y el pensamiento durante los primeros 36 años del siglo no sólo no tiene parangón con lo que pasó en su plástica (sus mejores artistas fueron artistas franceses), sino que los tiene muy escasos en cualquier rama de la cultura de cualquier época de ese país./ Pero tal vez no pasó nada de eso. O tal vez incluso la plástica española pesó en México más de lo que parece y sólo faltan los estudios inteligentes que nos lo hagan ver. Por eso es lo que hoy no podemos saber todavía y lo que acaso empieza a despertar nuestra curiosidad. La importancia por lo menos de esta exposición y el numeroso entusiasmo de los que la hicieron posible parece sugerirlo. Lo que no puede dudarse es que un acto de esta naturaleza que
} 
En España, la objetividad y el estudio o simple presentación de esta actividad artística tampoco eran cosa fácil. Por aquellas fechas varias galerías e instituciones privadas de Madrid y Barcelona, como el Ateneo y las galerías Multitud y Club Urbis, en la primera capital, y las galerías Pecanins y Dau al Set, en la segunda, también mostraron un renovado interés por los artistas exiliados y los orígenes vanguardistas de nuestro arte, aunque insistiendo principalmente en el exilio en París y en la conexión de nuestro arte avanzado con esta sancionadora metrópoli. El hecho, a pesar de esta importante inclinación, paralelamente sirvió para poner sobre la palestra a algunos artistas del exilio en México, como Rodríguez Luna, Arturo Souto, José Moreno Villa, Ramón Gaya, Joaquín Peinado, Aurelio Arteta, Cristóbal Ruiz, etc. ${ }^{6}$.

Hubo que esperar, pues, para que realmente comenzara el interés por el tema del exilio de una manera más profunda y sin soslayar el tema político, al pistoletazo de salida que, en el campo artístico, significó la exposición España. Vanguardia artística y realidad social, 19361976, presentada en la Bienal de Venecia de 1976. La muestra, luego llevada a Barcelona con algunas variantes, fue organizada por una amplia comisión de historiadores y artistas —entre los que hasta se encontraba José Renau, el viejo director general de Bellas Artes republicano-, y llegó incluso a reconstruir el Pabellón Español de la Feria Internacional de París de 1937, aunque lógicamente la muestra no pudo estar exenta de polémica, máxime cuando el catálogo fue retenido, por mandato judicial, ante el supuesto delito de propaganda ilegal ${ }^{7}$.

armoniza tantos esfuerzos y arroja tanta luz sobre un aspecto de lo que ha sucedido en arte en un país es para ese país un gran acontecimiento cultural» (Segovia, Tomás: [«Presentación»], Pintores y Escultores Republicanos Españoles en México, México D.F., Galería Mercedes y Jordi Gironella, 21-octubre-1975, s/p. Este catálogofolleto, también contiene textos de Fernando Gamboa y José Puche).

${ }_{6}$ Vid. entre algunas de estas muestras 12 pintores Españoles de la «École de París», Madrid, Ateneo, Sala Santa Catalina, 21 de mayo a 21 de junio de 1974 (con textos de Campoy y obra de Bores, Clavé, Domínguez, Guansé, Lagar, Parra, Peinado, Pelayo, Sales, De la Serna, Sobrado y Viñes). Orígenes de la vanguardia española, Madrid, Galería Multitud, noviembre-diciembre 1974 (con textos y documentación de J. Brihuega y obra de Alberti, Alberto, M. Ángeles Ortiz, Bores, Caballero, Cossio, Dalí, Domínguez, Ramón Gaya, García Lorca, Goméz de la Serna, Gris, Maruja Mallo, Moreno Villa, Olivares, Palencia, Peinado, Prieto, Arturo Souto, Togores, Torres García y Viñes). Surrealismo en España. Madrid, Galería Multitud, (Abril-Mayo) 1975 (con textos y documentación de F. Calvo Serraller y A. González García y obra de A. Buñuel, Caballero, Castellanos, Cristofol, Cuixart, Chirino, Dalí, Isaías Díaz, Domínguez, Ferrant, González Bernal, E. Herreros, Maruja Mallo, Massanet, Millares, Miró, J. A. Morales, Moreno Villa, Policarpo Niebla, Olivares, Palencia, Pérez Rubio, Picasso, Planells, Ponce de León, Ponç, A. Puig, Rodríguez Luna, A. Santos, Saura, Tàpies, Tharrats y A. del Valle). Cubismo, Madrid, Galería Multitud, junio 1975, con textos y documentación de Calvo Serraller y González García y obra, entre los españoles, de Blanchard, Bores, Isaías Díaz, Díaz Caneja, Julio González, Gómez de la Serna, Gris, Lahuerta, Martínez Ortiz, Olasagasti, Ginés Parra, Peinado, Pelegrin; Picasso, Pérez Mateos, Sandalinas y Vázquez Díaz). Exposición Conmemorativa de la Primera Exposición de Artistas Ibéricos, Madrid, Club Urbis, junio 1975 (con textos de Campoy y Brihuega y obra de Alberto, Arteta, Bagaría, Bores, Capuz, Cossio, Dalí, Echevarría, Macho, Palencia, Peinado, Cristóbal Ruiz, Sáenz de Tejada, Solana, Planes, Moreno Villa, Ucelay y los Zubiarre). El Surrealisme a Catalunya, Barcelona, Galería Dau al Set, noviembre de 1975 (con obra de Miró, Dalí, Massanet, Sandalinas, Sans, Cristófol, Marinello, Eudald Serra, Tàpies, Cuixart, Ponç, Tharrats, Vallés, A. Puig).

Vid. Bozal, V. y Llorens, T. (eds.): España. Vanguardia artística y realidad social, 1936-1976, Venecia, 10 junio-10 octubre 1976, Barcelona, G. Gili, «Col. Comunicación Visual», 1976. La comisión organizadora de la muestra y sus asistentes estuvo formada por varios artistas e historiadores: Tàpies, Saura, Ibarrola, Equipo Crónica, Josep Renau, Alberto Corazón, Oriol Bohigas, Pérez Escolano, Tomás Llorens, Valeriano Bozal, Inma Julián, José Miguel Gómez y Manuel García. La muestra tuvo tres secciones, una dedicada al arte y la realidad sociopolítica en la guerra civil, con la reconstrucción del citado Pabellón del 37; otra que de forma monográfica presentaba a artistas ligados a la actividad de ese momento: Picasso, Miró, Alberto, Julio González y Renau, y finalmente una tercera que mostraba un desarrollo crítico de la escultura y pintura desde entonces, con obra de numerosos artistas. Tras algunas modificaciones y en medio de gran polémica, de diciembre a febrero de 1977 se presentó en la Fundación Joan Miró («Avantguarda Artística i Realitat Social a l'Estat Espanyol: 1936-1976»). Para la ocasión, el catálogo, que no pudo ser comercializado por las razones referidas, fue publicado en forma de 
Pero además, ese mismo año iba a dar fe del gran interés que comenzaba a existir en torno al exilio, la publicación de los seis tomos de la obra dirigida por José Luis Abellán $E l$ exilio español de 1939, que, en el amplio plano cultural abarcado, incluía estudios sobre artes plásticas, arquitectura y cine y, pese a lo general de alguno, se convertiría en una obra de consulta imprescindible ${ }^{8}$.

Por otro lado, también 1976, (año del regreso de Renau, de la publicación de su libro Función social del cartel y de su participación en algunas exposiciones en España) ${ }^{9}$, es el de comienzo de un enorme interés por el cartelismo y el análisis del arte de la República y la guerra civil. Lo cual debe mucho a algunos de sus protagonistas, como Renau, Carles Fontseré o Jaume Miravitlles, y a los trabajos de investigadores como Inma Julián ${ }^{10}$, Josep Termes, Manuel García, Carmen Grimau, Eugenio Bustos y otros, que en conjunto lograron que este rico tema se incorporara a partir de entonces a nuestra historiografía artística.

Prueba de ello, sin duda, fueron las abundantes exposiciones organizadas en los años siguientes sobre el cartel republicano y bélico, que tuvieron, como más inmediatas plasmaciones tanto las muestras presentadas en 1977 en la Fundación Joan Miró y el Palacio de la Virreina de Barcelona, como en 1978 en el Centro Cultural de la Villa de Madrid ${ }^{11}$. Ocasiones acompañadas, además, de la aparición de interesantes testimonios y estudios sobre aquel importante momento del cartel ${ }^{12}$.

Esta actividad pionera consiguió, así, llevar a la escena historiográfica a toda una serie de artistas del exilio mexicano, relacionados con la república, la guerra y el cartel, (como Renau, Julián Oliva, Salvador Bartolozzi, José Bardasano, Luis Quintanilla, Ramón Gaya, Arturo Souto, Cristóbal Ruiz, Rodríguez Luna, Miguel Prieto, Ramón Puyol, Darío Carmona, Ramón Peinador, José Espert, Rivero Gil, Robles Ras, etc...), sobre quienes fue creciendo el interés por conocer y saber de su trayectoria posterior a la emigración.

libro. La revista Comunicación XXI, lanzó un número extraordinario titulado «Venecia 76. Toda una polémica» (n. ${ }^{\text {os }}$ 31-32, Madrid, 1977), donde reflejó todo el debate y ambiente vivido con esta exposición.

8 Dedicados específicamente a las materias indicadas, resaltam los siguientes estudios: Ballester, José M.a.: «El exilio de los artistas plásticos»; Sáenz de la Calzada, Arturo: «La arquitectura en el exilio» y Gubern, Román: «Cine español en el exilio», en Abellán, José Luis: El exilio español de 1939, t. V (Arte y Ciencia), 1976-1978, pp. 11-57, 59-89 y 91-188 (El resto de los volúmenes están dedicados: I: La Emigración Republicana; II: Guerra y Política; III: Revistas, Pensamiento Educación; IV: Cultura y Literatura; VI: Cataluña, Euzkadi, Galicia). Por otra parte, desde entonces también se comenzaría a conocer más sobre las instituciones gracias al libro de José M. a del Valle, Las instituciones republicanas en el exilio, París, Ruedo Ibérico, 1976.

9 Renau, J.: Función social del cartel (Prólogo de V. Aguilera Cerni e Introducción de Francisco Carreño), Valencia, Fernando Torres, 1976. Aparte de a la Bienal de Venecia y lo llevado a Barcelona, ese año también concurrió a la Mostra d'Art Actual del País Valencià, presentada por la Galería Canem de Castellón en Morella; aunque sus exposiciones individuales y verdadera presencia en la escena artística española comenzarían al año siguiente.

10 Inma Julián, por ejemplo, había publicado «El cartelismo y la gráfica en la guerra civil» en BozalLlorens: Op. cit., 1976, pp. 45-63, que suponía un avance de su tesis doctoral, y «Los carteles republicanos» en Comunicación XXI, 31-32, Madrid, 1977, pp. 61-67 y continuaría trabajando sobre el tema (vid. especialmente su libro El cartel republicano en la guerra civil, Madrid, ICROA, 1993).

$"$ Las primeras exposiciones fueron presentadas en mayo y junio de 1977 bajo los títulos de «Cartells polítics catalans dels anys 30» y «Cartells de la República i la Guerra» y, la tercera, entre octubre y noviembre de 1978 (Vid. Figueras, José M. (presentación): Carteles de la República y de la Guerra Civil, Madrid, Centro Cultural de la Villa, 23 oct.-17 nov. 1978).

12 Vid. Ruipérez, María: «Renau-Fontseré: Los carteles de la guerra civil» (entrevista), Tiempo de Historia, n.o 49, Madrid, dic. 1978, pp. 10-25; Miravitlles, Jaume; Termes, Josep y Fontseré, Carles: Carteles de la República y de la Guerra Civil, Barcelona, Centre d'Estudies d'Història Contemporánea-Ed. La Gaya Ciencia, 1978 y Grimau, Carmen: El cartel republicano en la Guerra Civil, Madrid, Cátedra, 1979. 
No obstante, el momento político era difícil. España empezaba a abordar ese fenómeno de cambio de estructuras sociopolíticas y culturales que hemos llamado «la Transición»y, pese a las demandas de algunos sectores sociales, a nivel oficial no era momento propicio para acercamientos a los exiliados ni, mucho menos, para el reconocimiento de las instituciones que les habían representado, especialmente el Gobierno de la República Española en el Exilio. Éste, sin embargo, había mantenido con México — desde la reunión de las Cortes Republicanas en la capital azteca, en 1945 - unas inmejorables relaciones, que en buena parte habían contribuido a su supervivencia, pero que ahora, ante la reanudación de las relaciones diplomáticas entre México y España, cortadas desde el desenlace de nuestro conflicto bélico, tocaban a su fin ${ }^{13}$.

El Gobierno republicano que había pervivido en el exilio, obviamente, no había obtenido nunca el reconocimiento del régimen del general Franco ni, como se ha dicho, podía conseguirlo ahora de los artífices políticos de la transición, «quienes consideraban como non grata e inoportuna incluso en esos momentos la mención de la palabra República», de hecho - se insiste- ni siquiera se legalizó, para que pudiera concurrir a las elecciones de junio de 1977, el partido de Acción Republicana Democrática Española (ARDE), al que pertenecían los últimos miembros del Gobierno de la República ${ }^{14}$.

A finales de ese mismo año, el restablecimiento de las relaciones entre México y España, sin embargo, iba a traducirse en la celebración, a modo de embajadas culturales, de exposiciones de arte patrocinadas por uno u otro Gobierno en las capitales de ambos países. Lo cual, por primera vez desde hacia muchos años, nos iban a acercar el arte de México a España y viceversa ${ }^{15}$. Incluso, esta nueva situación, iba a dar lugar a un fructífero comienzo

13 Sobre el hecho vid. Fuentes Mares, José: Historia de dos orgullos, México D.F., Océano, 1984, pp. 188212. Por otro lado, el nuevo y ambiguo momento de las relaciones entre España y México quedó bien reflejado en la prensa mexicana, como puede verse en los artículos del transterrado español José María Obregón Chorot, quien escribió asiduamente en Novedades bajo el seudónimo de J. M. Buendía, (recogidos en su libro España, ahora, México D.F., Publicidad Continental, 1980). Desde 1977 esta prensa fue perdiendo el interés, manifestado desde finales de 1975 ante la sucesión de Franco, por apoyar a los republicanos españoles, quienes quedaban en una situación difícil y ambigua (véanse los artículos de finales de 1975 y 1976 del mexicano Andrés Iduarte, recopilados en su libro En el fuego de España, México D.F., Joaquín Mortiz, 1982, pp. 277-305).

${ }_{14}$ Alted Vigil, Alicia: El Archivo de la República Española en el Exilio. 1945-1977 (Inventario del Fondo París), Madrid, F.U.E, 1993, p. 21.

${ }_{15}$ Esta relación era descrita en el mismo catálogo de la muestra celebrada en México, patrocinada por nuestro Ministerio de Cultura, Pintura Española del Siglo XX (Ciudad de México, octubre-diciembre 1978; textos de Felipe V. Garín Llombart y Álvaro Martínez Novillo), que presentaba a 102 pintores de lo más representativo del arte español del siglo, algunos de ellos (como Arteta, Camps Ribera, Blanchard, Bores, Clavé, Colmeiro, Óscar Domínguez, Julio González, Gris, Maruja Mallo, Moreno Villa, Picasso, Antonio Quirós, Vela Zanetti, Hernando Viñes, etc.) significativos exiliados durante mucho tiempo. Así, decía en su presentación Juan José Bremer, Director del Instituto Nacional de Bellas Artes (INBA) mexicano: «Para realzar el reestablecimiento de las relaciones diplomáticas entre México y España, los Gobiernos de ambos países decidieron presentar en Madrid y México exposiciones de arte en las que se exhibirían obras de importancia sustantiva. De tal manera, se manifestaría en forma por demás elevada en precio: La entrañable amistad que une a sus pueblos. Se mostrarían las obras más características del arte mexicano desde la época prehispánica hasta el presente y del arte español desde el renacimiento hasta nuestros días./ Cumpliendo con estos objetivos en el mes de octubre de 1977 se presentó una muestra de arte mexicano en el Museo de Arte Contemporáneo de Madrid, con asistencia del Presidente de la República Mexicana, Señor Licenciado José López Portillo y de su esposa, a dicha exposición./ Hoy, para festejar este acontecimiento de transcendencia histórica, que culmina con la visita a México de los Reyes de España Juan Carlos y Sofía, México recibirá una gran exposición dividida en dos partes, del arte español./ Esta primera, que tenemos el honor de presentar en el Museo de Arte Moderno comprende pinturas del siglo XX... En la segunda, que tendrá lugar en el Museo del Palacio de Bellas Artes en el mes de noviembre, se presentará la pintura española desde el período Renacentista hasta Goya.» (s/p). 
recopilador de testimonios y documentos sobre las relaciones entre México y la República Española y sus protagonistas ${ }^{16}$.

Allanado el camino, a partir de este momento se empezaría a funcionar a golpe de efemérides. Y, en 1979, se celebraba el 40 aniversario del exilio republicano en México. Este hecho fue ocasión de una destacadísima actividad en la capital azteca, en gran parte fomentada y protagonizada por el Ateneo Español de México, que organizó dos magníficas exposiciones en el Museo de San Carlos: Obra Impresa del Exilio Español en México y, sobre todo, en cuanto a arte, Obra Plástica del Exilio Español en México, que presentaba obra de más de 60 artistas transterrados, cuyo apunte significó un magnífico indicio de la fertilidad del fenómeno creativo durante el exilio ${ }^{17}$.

Pero también una institución fuertemente relacionada con los refugiados españoles, como El Colegio de México, organizó la exposición 40 Años de Emigración Española ${ }^{18}$, que al igual que las organizadas por el Ateneo acogió un amplio espectro artístico del exilio. Por otro lado, completando estas acciones, algunos diarios mexicanos dedicaron sus suplementos a diversas parcelas de la cultura española del destierro ${ }^{19} \mathrm{y}$ aparecieron, de la mano editorial, algunos libros de interés ${ }^{20}$.

\section{Los años 80: A golpe de efemérides}

La década de los setenta, pues, había puesto en escena los temas que más preocupaban y las fórmulas de acercamiento a ellos. A los años ochenta, así, les iba a corresponder ahondar

16 Vid. entre otras publicaciones del momento: Giral, Francisco y Santidrián, Pedro: La República en el exilio, Madrid, Ediciones 99, 1977; Becarud, J. y López Campillo, E.: Los intelectuales españoles durante la II República, Madrid, Ed. Siglo XXI, 1978; Hernández de León Portilla, Ascensión de: España desde México. Vida y testimonio de transterrados, México D.F., UNAM, 1978 y Matesanz, José Antonio (compilador): México y la República Española. Antología de Documentos, 1931-1977, México D.F., Centro Republicano Español de México, 1978.

${ }_{17}$ Vid. Xirau, Ramón (presentación): Obra impresa del exilio esapñol en México 1939-1979. Catálogo de la Exposición Presentada por el Ateneo Español de México, México D.F., INBA-SEP, Museo de San Carlos, 13 a 24 de noviembre de 1997; y Rius, Luis (presentación): Obra Pástica del Exilio Español en México, 1939-1979, México D.F., INBA-SEP, Museo de San Carlos, 14 a 22 de noviembre de 1979. Ambos catálogos, más otras actividades y trabajos programados por el Ateneo Español de México para conmemorar este 40 Aniversario, fueron recogidos también - con ligeras variantes- en la memoria, coordinada por Moisés Gamero de la Fuente, Homenaje a México, publicada en 1983 y de la que hablaremos más adelante (vid. nota 28).

${ }_{18}$ Vid. 40 Años de Emigración Española, México D.F., El Colegio de México, Sala Alfonso Reyes, 1979.

19 En especial el diario Novedades, que había estado muy vinculado a notables creadores españoles y les dedicó una edición especial de «La onda». Vid. AA.VV.: «Los republicanos españoles y la cultura mexicana» Novedades (Suplemento La onda, n.o 330, edición especial), México D.F., 7-octubre-1979, que contiene los siguientes artículos: Angeli, Jorge de: «Apostilla. Injerto fecundo», p. 2; Lage, Mario: «El exilio español y las artes plásticas. Entrevista con Elvira Gascón y Gerardo Lizárraga. Encuentro de dos pinturas adultas», pp. 2 y 5; Taibo, Paco Ignacio: «El exilio español y la televisión. La TV apaga las nostalgias», pp. 3-4; García Flores, Margarita: «El exilio español y la industria editorial. Joaquín Díez-canedo. La emigración buscaba mantenerse viva», pp. 6-7; Eguiluz, Lourdes: «Héroes que dignificaron al libro», pp. 6-7; Sáinz, Emilio: «El exilio español y la literatura. Sin ellos ya estaríamos embalsamados», p. 9; «El exilio español visto por los mexicanos. Encuesta. Fue la segunda conquista española», pp. 10 y 17; Estradera, Josefina: «El exilio español y la música. Una lección para todos. Entrevista con José Antonio Alcaraz», pp. 11 y 16; Río, Ricardo del: «El exilio español y el periodismo. Hemos dado, pero también hemos aprendido mucho», pp. 12-13; Arrieta Erdozain, Luis: «El exilio español y el cine. Enriquecieron y orientaron nuestra producción», pp. 13-15; Mejía, Eduardo: «El exilio español y la poesía. Nos enseñaron a escribir con entereza», p. 18 y Enríquez, José Ramón: «El exilio español y el teatro. Un hecho vivo del dolor», pp. 19-20.

${ }^{20}$ Contenían ya una clara distinción entre una primera y segunda generación de exiliados, como, entre ellos, Kenny, M.; García, A.; Inazuriaga, C.; Suárez, C. y Artis Gener, A.: Inmigrantes y refugiados españoles en México (siglo XX), México D.F., INAH-La Casa Chata, 1979. 
en esos cauces y materias ya abiertos. La conmemoración de fechas, a través de significativas exposiciones, fue una de las fórmulas que más relieve adquirió, ya que en esta década se cumplían diversos cincuentenarios relacionados con la República, la guerra civil y el exilio.

En principio, no obstante, en España continuó aumentando el interés por los temas de la guerra civil y el cartel, lo que, en definitiva, no era sino un remontarse a los orígenes del tema de este exilio y disponer de una buena —y necesaria — base de partida para el análisis de un fenómeno que, en su mayor parte, había sido consecuencia del conflicto bélico. Así, en Salamanca, se presentó en 1980 una gran exposición de carteles con los fondos de su Archivo de la Guerra Civil ${ }^{21}$ y, poco después, se inauguró en Madrid una de las más interesantes exposiciones sobre la guerra civil habidas hasta el momento, con secciones de arte, cine, carteles, etc. ${ }^{22}$; a lo que se sumaron algunas otras muestras relacionadas con relevantes aspectos artísticos del período bélico ${ }^{23}$. Y, este notable interés temático español por descubrir otras caras de ese transcendente momento de nuestra historia, también llegó al otro lado del Océano, donde - paralelamente- el Ateneo Español de México organizó una exposición sobre el cartel de la guerra civil ${ }^{24}$. Mientras, otras instituciones mexicanas, se lanzaron a recoger testimonios diversos sobre los refugiados españoles ${ }^{25}$.

Mas en 1981 llegó una primera e importante conmemoración, la del cincuentenario de la proclamación de la II República, que fue celebrada, en el Museo de Arte Carrillo Gil de México, con una exposición en favor de la creación de un Centro Republicano Español ${ }^{26}$. Sin embargo, aparte de ésta y otras muestras ${ }^{27}$, en el México de comienzos de los ochenta destacó más la publicación de estudios sobre la aportación del exilio español. Entre éstos, sin lugar a dudas, sobresale el magnífico volumen conjunto, dirigido por Salvador Reyes Nevares y presentado por el propio presidente de la República, José López Portillo, El exilio español en

${ }^{21}$ Vid. Bustos, Eugenio (textos) y Jiménez Buendía, Paloma (catálogo): Exposición de Carteles de la Guerra Civil Española, Salamanca, Escuela de Nobles y Bellas Artes de San Eloy, junio 1980, (patrocinada por el Ministerio de Cultura).

${ }^{22}$ Vid. AA.VV. (Manuel García y otros): La Guerra Civil Española, Madrid, (Ministerio de Cultura), Palacio de Cristal del Retiro, octubre-diciembre 1980. Con secciones sobre Arte, Cine, Carteles, Fotografías, Prensa, Numismática, Filatelia, Armas, Uniformes; Entrevistas y Apartado de Documentación Gráfica sobre la guerra civil (incluye descripción de archivos, fondos, etc.).

23 En 1980, entre otras, también se presentó en Madrid la exposición 12 Artistas catalanes de 1937. Obras incautadas a la Generalitat de Cataluña, Madrid, Palacio de Congresos y Exposiciones, 1980.

${ }_{24}$ Fue celebrada en noviembre en las propias salas del Ateneo y en ella se presentaron carteles de Renau, Bardasano, Germán Horacio, Bartolozzi, etc. (v. Domínguez Aragonés: «Carteles de la guerra civil en el Ateneo Español de México», El Sol de México, 2-noviembre-1980, pp. 1, 4 y 5).

${ }_{25}$ Especialmente el Instituto Nacional de Antropología e Historia mexicano (INAH) y otras instituciones, que ese año dieron comienzo a la publicación de una interesante recopilación de testimonios, en la serie «Palabras del Exilio», coordinada por Eugenia Meyer. (v. Meyer, Eugenia (coor.) y otros: Palabras del Exilio. 1. Contribución a la historia de los refugiados españoles en México, México D.F., INAH (SEP)-Librería Madero, 1980; Palabras del Exilio. 2. Final y comienzo: El Sinaia, México D.F., INAH (SEP)-Librería Madero, 1982; Palabras del Exilio. 3. Contribución a la historia de los refugiados españoles en México. Seis antropólogos mexicanos, México D.F., INAH (SEP)-Librería Madero, 1984 y Palabras del Exilio. 4. De los que volvieron, México D.F., INAH (SEP)-Instituto Mora, 1988).

${ }^{26}$ La muestra del Museo de Arte Carrillo Gil estuvo auspiciada por el INBA. Se organizó en favor de la creación de la sede de un Centro Republicano Español y en ella participaron bastantes artistas transterrados (vid. Pro Casa Centro Republicano Español, México D.F., (Instituto Nacional de Bellas Artes-SEP), Museo de Arte Carrillo Gil, 1981)

27 En Valencia, por ejemplo, también se celebró en 1981 la exposición «La vanguardia artística valenciana de los años treinta», organizada por el Ayuntamiento y que recogía obra de Renau, Climent, Antonio Ballester y Manuela Ballester, entre otros. 
México, aparecido en 1982 y rápidamente convertido en una de las obras más importantes que abordan la complejidad del fenómeno del exilio, incluida la producción artística ${ }^{28}$.

En nuestro país, en cambio, el conocimiento del exilio mexicano avanzó más a través de muestras, destacando el año 1983, en el que, si bien fueron de gran interés exposiciones como «Llegat Fabrega-Pintors catalans a l'exili», presentada en Figueras por el Museu de l'Empordá ${ }^{29}$, o «Pintado en México», patrocinada por el Banco Exterior en Madrid y a la que se concedió un gran relieve diplomático ${ }^{30}$, sobresalieron principalmente dos grandes exhibiciones organizadas por el Ministerio de Cultura. Esto es la itinerante, comisariada por Manuel García, titulada De la guerra civil al exilio republicano, que prestó especial atención al cartel ${ }^{31}, \mathrm{y}$, sobre todo, la exposición El exilio español en México, presentada en diciembre en el Palacio de Velázquez madrileño (en 1984 fue llevada a Barcelona), cuya exhibición de cuadros, esculturas, libros, carteles, fotografías, revistas, audiovisuales, etc. intentaba ofrecer una amplia visión de la obra de los exiliados en los diferentes campos de la cultura. Así, solamente en la sección de arte, contó con obra de unos 25 artistas exiliados, entre pintores, escultores y arquitectos y fue la primera vez que en España se exponía una muestra de estas características, con el objetivo expreso — según su comisario — de «recuperar para nuestro país la obra de unos españoles arrancados de él, que han seguido viviendo a España desde fuera» ${ }^{32}$.

En el resto de la década, diversas exposiciones y escritos, continuaron aportándonos nuevos datos y aumentando los testimonios y el conocimiento directo sobre la historia de la República Española, èl exilio, la plástica y las relaciones hispano-mexicanas ${ }^{33}$; incluso sobre

${ }^{28}$ Vid. López Portillo, José: «Prólogo», y Souto Alabarce, Arturo: «Pintura», «Música y danza», «Arquitectura», «Escultura» y «Fotografía», en Reyes Nevares (dir.): El exilio español en México, 1939-1982, México D.F., Salvat-FCE, 1982, pp. 9-12, 433-470, 471-481, 483-488, 489-491 y 492-493, respectivamente. A esta obra se unió al año siguiente una importante memoria del Ateneo Español de México, sobre las actividades que se promovieron en 1979: vid. Gamero de la Fuente, Moisés (coor. y dir.): Homenaje a México. Historia Contemporánea de una emigración. España 1939-México 1979, México D.F., Ateneo Español de México, 1983. La memoria, ampliamente ilustrada con dibujos para la ocasión de Elvira Gascón y obras plásticas que fueron expuestas en la muestra del Museo de San Carlos de 1978, contine la reproducción de los catálogos de 1979 —vid. nota 17-, discursos y presentaciones, conferencias, lecturas de poemas, estudios, mesas redondas, etc. de las actividades conmemorativas realizadas en 1979 en México y Veracruz. Por otro lado, diferentes estudios y aportaciones, vinieron en estos años a arrojar más luz sobre el exilio, como, entre otros, Martínez Feduchy, Manuel: Los amenos senderos del exiliado. (La República Española de 1931 a 1977), México D.F., Edición del autor, s./a. (1982); Hernández de León-Portilla, Ascensión: «Cultura española en México», Historia 16, n.. 80, Madrid, dic. 1982, pp. 10-18; «La España Transterrada y sus Aportes», Tiempo, n.․ 2115, México D.F., 15-nov.-1982, pp. 9 18, o Abellán, José Luis: De la guerra civil al exilio republicano (1936-1977), Madrid, Mezquita, 1983.

${ }_{29}$ Llegat Fabrega-Pintors catalans a l'exili, Figueres, Museu de L'Emporda, 1983

30 Ullán, José Miguel (coor.): Pintado en México, Madrid, Banco Exterior, noviembre 1983. Su inauguración - 4 de noviembre - contó con la presencia de los ministros españoles de Cultura y Presidencia y el poeta mexicano Octavio Paz. Exponían Gunther Gerzo, Juan Soriano, Manuel Felguerez, Alberto Gironella, Vicente Rojo, Roger Von Gunten, José Luis Cuevas y Francisco Toledo.

31 Vid. especialmente los textos de García i García, Manuel: «Aproximación al arte español durante la guerra de 1936 a 1939» y Fontseré, Carles: «Consideraciones sobre el cartel de la guerra civil» en La Guerra Civil Española (exposición itinerante), Madrid, Ministerio de Cultura, 1983, pp.15-26 y 37-46, respec.

${ }_{32}$ González, Pedro (comisario): («Presentación»), en El exilio español en México, Madrid, Palacio de Velázquez, diciembre 1983-febrero 1994, p. 35 (Textos de José Luis Abellán, Francisco Giner de los Ríos, Manuel Andújar y Fernando Serrano Migallón).

${ }_{33}$ Vid. Fuentes Mares: Op. cit.; Zelaya Kolker, Marielena: Testimonios americanos de los escritores españoles transterrados de 1939, Madrid, Cultura Hispánica, 1985; Pla Brugat, Dolores: Los niños de Morelia, México, INAH, 1985; Frida Kahlo, Vicente Rojo, Manuel Álvarez Bravo, Madrid, Salas Ruíz Picasso, 30 abril-15 julio 1985 (Tres exposiciones organizadas por el Museo Tamayo y la Secretaría de Educación Pública (SEP) mexicanos y el Ministerio de Cultura español). 
temas más concretos, como el desarrollo del cartel publicitario o los carteles y el fotomontaje de notables personajes como Renau ${ }^{34}$. Pero, realmente, las aportaciones más importantes llegaron en la segunda mitad de los años ochenta, con la conmemoración de varios cincuentenarios.

Así, Valencia celebró el cincuenta aniversario de su capitalidad durante la República con la exposición: «Valencia, capital de la República» ${ }^{35}$ y conmemoró el Congreso Internacional de Intelectuales y Artistas Antifascistas de 1937 con la exposición «50 años después» ${ }^{36}$; a la vez que financió destacadas publicaciones dedicadas al estudio de la labor de los artistas en la Valencia de la guerra y en el exilio ${ }^{37}$. Mientras, con precedente en Barcelona ${ }^{38}$, el Centro de Arte Reina Sofía conmemoró en Madrid el cincuentenario del Pabellón Español de 1937, reconstruyéndolo en una exposición que sacó a la luz obra, que se tenía por perdida, de un gran número de artistas, entre ellos varios de los desterrados en México: Rodríguez Luna, Gaya, Miguel Prieto, Climent, Ramón Puyol, Arteta, Renau, Souto o el mismo Buñuel ${ }^{39}$.

Además hay que añadir, en el sentido de progresivo conocimiento artístico que nos interesa, que paralelamente a estas ocasiones de recuerdo, se fueron uniendo otras que homenajeaban a artistas determinados, como fue el caso de la celebración del centenario del nacimiento de una las figuras más representativas y polifacéticas del exilio mexicano: José Moreno Villa, redescubierto ahora como pintor, tanto en España como en México, a través de una gran exposición antológica ${ }^{40}$. Y como fueron los casos de Cristóbal Ruiz y Remedios Varo -ésta ya muy conocida en los medios mexicanos e internacionales-, de quienes se recordaron los

${ }^{34}$ Vid. Renau, cartelles de cinéma, Barcelona, Sala de Exposiciones Caixa de Pensions, diciembre 1984enero 1985 (sobre los carteles de cine que éste realizó en su exilio mexicano); Renau, Josep: Josep Renau, fotomontador (Presentación de Joan Fontcuberta), México D.F., FCE, 1985 y 100 años del cartel publicitario (publicidad comercial 1875-1975), Madrid, Centro Cultural del Conde-Duque, marzo-abril 1985, (que, entre otros muchos, presentaba carteles realizados por Bardasano, Bartolozzi, etc.).

${ }^{35}$ Vid. del catálogo de la misma especialmente los artículos: Agramunt Lacruz, Francisco: «La pintura valenciana»; Blasco Carrascosa, Juan Ángel: «La escultura en Valencia durante la Segunda República» y Tomás Ferre, Facundo: «Carteles valencianos en la guerra civil», en València, capital de la República, Valencia, Ajuntament de València, 1986, pp. 75-78, 79-80 y 81-83, respec.

36 Vid. 50 años después, Valencia, Generalitat Valènciana, 1987

37 Vid. Pérez Contel, Rafael: Artistas en Valencia 1936-1939 (2 vol.), Valencia, Generalitat Valenciana, 1986; AA.VV. (Aznar Soler, M. y otros): València capital cultural de la República (1936-1937). Antología de textos $i$ documentos, Valencia, Generalitat Valenciana, 1986. También un número de la revista Batlia se dedicó a los valencianos en relación a la guerra y el exilio; interesando especialmente los artículos de García, Manuel: «Trayectoria mexicana de José Renau (1939-1958)», «Testimonios. Enrique Segarra. El señor arquitecto» (entrevista), «Octavio Paz: Libertad bajo palabra» (entrevista) y «Presencias mexicanas en Valencia (36-39): Cabada, Chávez y Gamboa», y de García Ponce, Juan: «Enrique Climent, inesperada pirueta», Batlia, n.․․ 5, Valencia, Otoño-Invierno 1986, pp. 66-75, 103-107, 139-145, 146-157 y 77-79, respectivamente.

38 Vid. Arte Contra la Guerra, Ajuntament de Barcelona. Entorn del Pavelló Espanyol a l'Exposició Internacional de París, 1937, Barcelona, Palau de la Virreina, Nov.-Dic. 1986

39 Vid. Alix, Josefina (comisaria): Pabellón Español 1937: Exposición Internacional de París, Madrid, Centro de Arte Reina Sofía, 25 junio-15 septiembre, 1987. Por otro lado, en México también se recordaron estas fechas y la UNAM, por ejemplo, preparó una recopilación hemerográfica sobre el tema de la República y el Exilio españoles: Cano, Aurora y Creel, Celia (responsables): La República Española y el Exilio (recopilación hemerográfica), Nuestro Tiempo, n.o 18, México D.F., UNAM, 1987, pp. 1 a 55. Además hay que tener en cuenta que la temática e investigación sobre el exilio comenzó en estos momentos a interesar fuertemente a las diferentes políticas culturales de las Comunidades Autónomas españolas, véase como ejemplo en Euskadi: Koldo San Sebastián: $E l$ exilio vasco en América. 1936-1946. Acción del Gobierno, San Sebastián, Ed. Txertoa/Dpto. de Cultura y Turismo del Gobierno Vasco, 1988.

${ }^{40}$ Vid. Pérez de Ayala, Juan (Edición): José Moreno Villa, 1887-1955, Madrid (Ministerio de Cultura), Biblioteca Nacional, Salas Ramón Carande, abril-mayo, 1987 y Pérez de Ayala (comisario): José Moreno Villa, 1887-1955, México D.F, (INBA-SEP), Museo Nacional de Arte, abril 1988. 
25 años de su fallecimiento en tierras mexicanas ${ }^{41}$; mientras respecto a otros, como Renau o Ramón Gaya, fue habiendo oportunidad en España, desde finales de los setenta, de conocer su obra y homenajearles ${ }^{42}$.

Con todo, el colofón de las conmemoraciones de la década se iba a poner en 1989, con motivo de la celebración del 50 Aniversario del Exilio Español de 1939. La ocasión, de cierto relieve en España, donde —entre las actuaciones más significativas- destacaron las coincidentes celebraciones en Madrid, en el mes de noviembre, del simposio internacional «El destierro español en América: un trasvase cultural», realizado en el Centro Cultural de la Villa, con el patrocinio del Instituto de Cooperación Iberoamericana, la Universidad Internacional Menéndez Pelayo y la Comunidad de Madrid, y de la exposición «Cincuenta años de exilio español», organizada por la Fundación Pablo Iglesias en el Parque del Retiro ${ }^{43}$, resultó muy fructífera en publicaciones en México, donde los suplementos de algunos diarios de la capital azteca, como los de El Nacional (Textual y Revista Mexicana de Cultura) ${ }^{44}$, y

41 Vid. AA.VV.: Cristóbal Ruiz, 1881-1962. Exposición antológica, Jaén (Diputación Provincial), Palacio Provincial, enero-febrero 1987 (Textos de C. López Carvajal, Cesáreo Rodríguez Aguilera, Julián Gállego, Manuel Andujar, Castro Arines, Ricardo Gullón, F. Soriano, Miguel Viribay y Manuel Urbano). Remedios Varo: 1913-1963, México D.F., Museo de Arte Moderno, agosto-octubre, 1983; Sciencie in Surrealism: The Art of Remedios Varo, Nueva York, New York Academy of Sciences, 20 mayo-18 julio (y Washington D.C., Nacional Academy of Sciences, 17 sep.-21-nov.), Seseña, Natacha y otros (textos): Remedios Varo, Madrid, Fundación Banco Exterior, Sala de Exposiciones, noviembre 1988-enero 1989.

${ }_{42}$ Este último, Gaya, había vuelto en 1960 a España, realizando una exposición en Madrid de escaso eco (Ramón Gaya, Madrid, Galería Mayer, abril 1960, óleos, pasteles y gouaches). En 1974 participó en la colectiva Orígenes de la vanguardia española, de la Galería Multitud (vid. nota 6) y en 1975 realizaba una nueva muestra en Valencia (Massoni, Luis: Ramón Gaya, Valencia, Galería Garby, diciembre 1975), hasta que en 1978 se celebró una antológica en Madrid (Bergamín, José; Calvo, Julián y otros: Ramón Gaya, Madrid, Galería Multitud, 1978) que representó el verdadero inicio de su recuperación. Así, en 1980, con motivo de sus 70 años, se celebra en Murcia una antológica y se publica un libro de homenaje con una antología de textos sobre el pintor (Agamben, Giorgio; Andújar, Manuel; Azcoaga, Enrique y otros: Homenaje a Ramón Gaya, Murcia, Editora Regional de Murcia, 1980). En 1984, la Generalitat de Valencia, las Diputaciones de Valencia, Alicante y Castellón y la Caja de Ahorros de Alicante y Murcia realizan una gran exposición antológica de su obra (Nigel, Denis; Bergamín, José; Flores, F. y otros: Ramón Gaya, Valencia, Museo de Bellas Artes de San Pío V, febrero 1984). En junio de 1985 el Ministerio de Cultura le concede la Medalla de Oro en Bellas Artes y en 1987 expuso en Valencia medio centenar de obras en la muestra ya referida «50 años después» y en 1989 el Ministerio de Cultura y la Comunidad de Murcia organizaron una gran exposición antológica de su obra en Madrid y Murcia (Salazar, M. José (comisaria): Ramón Gaya. Pintura. 1922-1988, Madrid-Murcia, MEAC (feb.-marzo)-Iglesia de San Esteban (marzo-abril). Textos de J. Bergamín, J. M. Bonet, F. Flores, J. Gállego y A. E. Pérez Sánchez).

${ }_{43}$ Sobre la significación de estos eventos y otros que tuvieron lugar en el mismo año en México (México D.F. - UNAM - , Puebla y Veracruz), Puerto Rico, Maryland (EE.UU.) y España, véase el comentario de Nicolás Sánchez-Albornoz a la publicación de las actas del simposio citado: Sánchez-Albornoz, N. (compilador): «Prefacio» en AA.VV.: El destierro español en América: un trasvase cultural, Madrid, Sociedad Estatal Quinto Centenario-ICI, 1991, pp. 11-14.

44 Vid. Matesanz, José Antonio: «Cárdenas y la República Española», Álvarez Valdés, Cosme: «Entrevista con Ramón Xirau», Xirau, Ramón: «Poetas españoles en México: desterrados y transterrados», Carrillo Marcor, Alejandro: «Mi acercamiento a la República Española»; Nicol, Eduardo: «El autor y su obra. La revolución en la filosofía» en «50 Años de Exilio Español en México», Textual (El Nacional), Vol. 1, n.․2, México D.F., junio 1989, pp. 4-10, 11-14, 15-18, 19-22 y 23-24, respec. Sánchez Vázquez, Adolfo: «Recordando al Sinaia», Álvarez, Federico: «El pensamiento perdido»; Souto, Arturo: «La imagen de México en los poetas españoles»; Mantecón, Matilde: «La labor editorial de los refugiados españoles», Rejano, Juan: «Memorabilia. Primer escenario de América»; Pla, Dolores: «Los niños de Morelia»; Ramos, Luis Arturo: «Los que vinieron por mar»; Muñiz, Angelina: «Reconciliación» (poema); Domenichina, Juan José: «18 de diciembre» (poema); Capella, M..$^{\underline{a}}$ Luisa: «La primera mirada»; Gamboa, Rafael G.: «El exilio español y el cine», en «A cincuenta años del exilio español», El Nacional (Revista Mexicana de Cultura, n.o 332), México D.F., 2-julio-1989, pp. 2-4, 5, 6-7, 7-8, 9, $10-12,13,14,14,15$ y 16 , respec. 
varias revistas, como Omnia y México en el Arte ${ }^{45}$, dedicaron números monográficos a la notable presencia de los exiliados españoles en México ${ }^{46}$.

Igualmente, con idéntico motivo, pero a través de la exhibición del testimonio artístico, el Museo de San Carlos de México inauguró la exposición, nuevamente presentada por el Ateneo Español, Obra plástica del exilio español en México, en la que se mostraba obra de más de 61 artistas transterrados ${ }^{47}$. Aunque, respecto al conocimiento de la creación plástica española en la hospitalidad de este país, la exposición, más confirmaba una nómina de artistas, que avanzaba sobre la aportación compiladora que había supuesto la muestra presentada diez años antes en el mismo Museo.

\section{Los años 90: Un tema pendiente de estudio}

En realidad, pues, a finales de los años ochenta se continuaba sin una investigación en profundidad, verdaderamente significativa y representativa, del fenómeno artístico del exilio y sus protagonistas. Y, en las pocas aproximaciones que, ya en la década de los noventa, han abordado de una otra forma este tema, aunque se ha conseguido ampliar más la información a nivel general, el estudio amplio y ponderado ha seguido quedando pendiente ${ }^{48}$.

${ }^{45}$ Vid. Alba Aldave, Fernando: «Presentación»; Giral, Francisco: «Conmemoración oficial de los 50 años del exilio español en México»; Vargas Lozano, Gabriela: «Cincuenta años del exilio español: la filosofía»; Capella, M..$^{\mathrm{a}}$ Luisa: «La primera mirada»; Guarner, Enrique: «Reflexiones psicológicas acerca de los refugiados españoles»; Rius, Pilar: «Evocación alquimica de Nepantla»; Perales Ojeda, Alicia: «La aportación del exilio español a la bibliografía nacional de México»; Ruiz, Alberto: «La segunda generación de escritores exiliados de México»; Palazón, Ana M...” «El exilio republicano en la educación mexicana»; Palazón, M. ํㅜ Rosa: «Pedagogía y vida. Posibles sugerencias para México de la filosofía de la educación de Joaquín Xirau», en Omnia, n.․․ 17, México D.F., diciembre 1989, pp. 3, 5-8, 9-16, 17-20, 21-28, 29-32, 33-42, 43-46, 47-52, 53-60 (ilustraciones con la obra de Enrique Climent, R. Fernández Balbuena, Elvira Gascón, F. Moreno Capdevila, J. Moreno Villa, A. Rodríguez Luna, A. Souto, Lucinda Urrusti y Remedios Varo). Álvarez, Federico: «España y su conocimiento de América. Por un nuevo latinoamericanismo español»; Pla Brugat, Dolores; «El exilio español en México: composición y perpectivas de análisis»; Soler, Martí: «La literatura catalana en el destierro» en México en el Arte, n.․ 22, México D.F, verano 1989, pp. 65-71, 73-76 y 76-77, respec. (dibujos de José Bartolí).

46 Incluso se hicieron ediciones facsímilares de míticas revistas de los refugiados, como Sinaia (vid. Sinaia. Diario de la Primera Expedición de Republicanos Españoles a México, Presentación y epílogo de Adolfo Sánchez Vázquez, México D.F., UNAM/UAM/La Oca/ Redacta, 1989 [1939]).

${ }_{47}$ Vid. Gamboa, Fernando y Ulacia, Manuel (texto): Obra Plástica del Exilio Español en México. 50 Aniversario del Exilio Español (1939-1989). Exposición Presentada por el Ateneo Español de México, México D.F., Museo de San Carlos, sep.-oct. 1989.

${ }_{48}$ Aparte de las exposiciones antológicas y homenajes a algunos pintores (Rodríguez Luna, Ramón Gaya, Remedios Varo, Roberto Fernández Balbuena, Vicente Rojo, etc.), que se han producido desde entonces y que nos han permitido conocer mejor su obra, entre lo más significativo, en varios aspectos —especialmente el contextualizador de esta creación artística-, publicado en estos últimos años, destacaría: Enríquez Perea, A. (introducción y recopilación): México y España: Solidaridad y Asilo Político 1936-1942, México D.F., SEP, 1990; Mateo, Eduardo: «El exilio español de 1939» y Giral, Francisco: «Ética de la política. El exilio en México» en Cuadernos Republicanos, n.․ 4, Madrid, octubre 1990, pp. 37-64 y 69-72 respec.; AA.VV. (Hugo Aréchiga y otros): Cincuenta años del exilio español en la UNAM, México D.F., UNAM, 1991; Naharro-Calderón, J. M. (Coord.): El exilio de las Españas de 1939 en las Américas: «Adónde fue la canción?», Barcelona, Anthropos, 1991; Sánchez-Albornoz, Nicolás (compilador): Op. cit., 1991; Sánchez Vázquez, Adolfo: Del exilio en México. Recuerdos y reflexiones, México D.F., Grijalbo, 1991; Agramunt Lacruz, Francisco: Un arte valenciano en América. Exiliados y emigrados, Valencia, Generalitat Valenciana, 1992; Climent Beltrán, Juan Bautista: Crónica de Valencia. Escritos desde el exilio, Valencia, Generalitat Valenciana, 1992; Galí, Montserrat: Artistes Catalans a Mèxic. Segles XIX i XX, Barcelona, Generalitat de Catalunya-Comissió América i Catalunya 1992, 1993; Alted Vigil, A.: Op. cit., 1993; Tussell, Javier, Martínez-Novillo, Álvaro y Uhrova, Olga (comisarios): Artistas españoles de París: Praga 1946, Madrid (Caja Madrid), Sala de Exposiciones Casa del Monte, dic. $1993-$ enero 1994; Amalric, Jean-Pierre y Julia, Santos (dirs.): Exilios. Refugiados españoles en el Mediodía de Francia, 
Resumiendo, pues, podríamos decir que, abiertas las posibilidades en 1975, fundamentalmente han sido tres los factores que más han contribuido a ampliar nuestro conocimiento sobre los artistas españoles del exilio mexicano y su producción. En primer lugar, el interés despertado en España por los temas relacionados con el arte de la guerra civil y el desarrollo del cartelismo; en segundo, el restablecimiento de las relaciones diplomáticas entre México y España y el intercambio cultural aparejado y, finalmente, la actividad derivada en España y México de las conmemoraciones relacionadas con la República, la guerra civil y el 40 y 50 aniversario del exilio. A lo que habría que sumar las diferentes ocasiones, más particulares, de recuerdo $\mathrm{u}$ homenaje sobre algunos artistas relacionados con el exilio.

También podemos evocar lo significativo que fue para España las conmemoraciones del año 1992. Le precedió casi un lustro en el que los estudios e investigaciones relacionadas con Latino-América fueron un área prioritaria en nuestro país y, el tema del exilio español al otro lado del Oceáno, supo asociarse convenientemente a esta circunstancia en varias ocasiones. En ese mismo 1992, llegó el momento de sacar a la luz publicaciones como las de Francisco Agramunt y Juan Bautista Climent sobre artistas y temas valencianos, el escogido volumen coordinado por José María Naharro-Calderón, la amplia visión sobre los artistas de Montserrat Galí o cursos sobre el exilio valenciano como los que dirigieron Albert Girona y María Fernanda Mancebo ${ }^{49}$. En todos ellos, por otra parte, es perceptible la disgregación geográfica o regional del tema del exilio, parcelado las más de las veces según los intereses de las diferentes Comunidades Autónomas españolas, lo cual, mientras se haya tenido en cuenta — que no siempre ocurre - una clara visión de conjunto del fenómeno, no creo que deba ser reprochable.

Hay que hacer notar, con todo, que han sido diferentes los enfoques y áreas de intereses en uno y otro país tratado. Puesto que si, en México, el exilio español ha interesado especialmente en cuanto fenómeno sociológico y de aculturación; en España, ha interesado más como una significativa consecuencia de la guerra civil, aunque con el tiempo comiencen a aparecer otras lecturas. De este modo, si en los estudios del historiador mexicano - y no tanto el exiliado-, se aprecia que la República y la guerra civil, apenas suelen constituir una méra introducción que explique las causas del asiento y prolongado exilio español en México, vemos que, en los del español de acá, el exilio, apenas suele tratarse como un mero apéndice de los resultados de aquel enfrentamiento bélico. Y, esta diferencia de enfoques, demasiado determinante, se refleja claramente en las aproximaciones que ha tenido, bien en México o bien en España, el estudio del arte que se nos desarrolló bajo los especiales condicionantes de esos largos cincuenta años de destierro.

La incidencia de este peculiar contexto en el mundo creativo, como no podía ser de otro modo, fue dotando a la diversidad de este arte de unas características que le son propias y le proporcionan su singular identidad frente a otros fenómenos y florecimientos artísticos. Pero

\footnotetext{
Madrid, UNED, 1994; Aznar Soler, Manuel (edición)-Gexel: Las literaturas exiliadas en 1939, Barcelona, Associació d'Idees-Gexel, 1995; Girona, Albert y Mancebo, M. ${ }^{a}$ Fernanda (Eds.): El exilio Valenciano en América. Obra y Memoria, Valencia, Instituto de Cultura Juan Gil-Albert/Universitat de Vàlencia, 1995 (la obra recoge los trabajos presentados al curso sobre los exiliados, dirigido por Girona y Mancebo, de la Universidad Internacional Menéndez Pelayo de Valencia en 1992); Piedrafita Salgado, Fernando: Fondo Hemerográfico del Archivo de la II República en el Exilio, Madrid, FUE, 1996; Cabañas Bravo, Miguel: Artistas contra Franco. La oposición de los artistas mexicanos y españoles exiliados a las Bienales Hispano-Americanas de Arte, México D.F., UNAM, 1996; AA. VV. (J. L. Abellán, Juan Marichal, Rafael Segovia et alii): Los refugiados españoles y la cultura mexicana. Actas de las primeras jornadas, celebradas en la Residencia de Estudiantes en noviembre de 1994, Madrid, Publicaciones de la Residencia de Estudiantes, 1998.

49 Sobre esta producción véase la nota anterior.
} 
lo cierto es que aún nos resta enfrentarnos a fondo con la gran amplitud de la obra y la circunstancia que enseguida se presiente cuando hablamos del exilio. Establecer criterios de estudio, documentar obras y artistas y medir los alcances de los hechos que le enmarcan serían algunas de las tareas más urgentes que nos situarían ante el conjunto de características que ahora, tan vaga e intuitivamente, nos permite identificar este arte. Mas, previo a esto, conviene reflexionar sobre lo que ha interesado y como ha sido visto y tratado el fenómeno del exilio de los artistas republicanos españoles desde la historia del arte. Hallaremos entonces que, esta segunda parte de la historia de este «transtierro», tampoco ha podido alejarse de las nuevas circunstancias. 